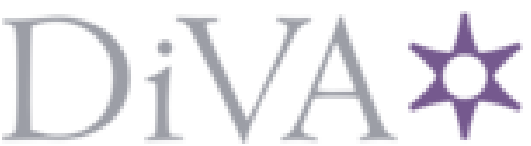

http://www.diva-portal.org

\title{
Postprint
}

This is the accepted version of a paper published in . This paper has been peer-reviewed but does not include the final publisher proof-corrections or journal pagination.

Citation for the original published paper (version of record):

Abelsson, A., Lundberg, L. (2018)

Trauma simulation in prehospital emergency care

Journal of Trauma Nursing, 25(3): 201-204

https://doi.org/10.1097/JTN.ooooooooooooo370

Access to the published version may require subscription.

N.B. When citing this work, cite the original published paper.

Permanent link to this version:

http://urn.kb.se/resolve?urn=urn:nbn:se:hj:diva-40711 


\section{Trauma simulation in prehospital emergency care}

Abelsson $\mathrm{A}^{1^{*}}$ Lundberg $\mathrm{L}^{2,3}$

Anna Abelsson*, RN, PhD.

* Corresponding author

${ }^{1}$ Jönköping University, School of Health Sciences, Jönköping, Sweden

Email: anna.abelsson@ju.se

Lars Lundberg, MD PhD, Professor

${ }^{2}$ Swedish Armed Forces Centre for Defence Medicine, Göteborg, Sweden

${ }^{3}$ PreHospen - Centre for Prehospital Research, University of Borås, Borås, Sweden 


\begin{abstract}
Introduction: Well-educated ambulance staff is a prerequisite for high-quality prehospital trauma care. The aim of this study was to examine how nurses in the ambulance service experienced participation in trauma simulation.
\end{abstract}

Methods: Sixty-one nurses, working in an emergency ambulance service, performed simulated trauma care on four different occasions and afterward rated three statements on a 5point Likert scale. A descriptive and inferential analysis were conducted.

Results: There are statistically significant increases between the pre- and post-test regarding all three statements; "I think simulation of severe trauma with manikins is realistic" (.23 or $6 \%$ increase), "Simulation is a suitable method for learning severe trauma care" (1.3 or 38\% increase), and "I am comfortable in the situation learning severe trauma care through simulation" (.74 or $19 \%$ increase).

Discussion: With the experience of realism in simulation, participants become more motivated to learn and prepare for future events. If the participants instead feel uncomfortable during simulation training, they focus on their own feelings instead of learning.

Conclusion: In a realistic simulated environment, participants are prepared to understand and manage the emergency care situation in clinical work. Participants learn during simulation when they are outside their comfort zone but without being uncomfortable or experiencing anxiety.

Keywords: simulation; trauma, ambulance; prehospital emergency care 


\section{Introduction}

In Sweden, the National Board of Health and Welfare (2015) defines trauma as "patient with apparent or suspected life-threatening injury, or where there is a risk of persistent serious disability" (National Board of Health, 2015, p. 60). Traumatic injuries in a prehospital setting may be caused by both blunt and penetrating mechanisms (PHTLS, 2014). Globally, every year around 6 million people are killed by injuries. In addition, millions of people are injured temporarily or permanently. Traumatic injuries are increasing significantly in the whole world and represent $9 \%$ of the world's deaths yearly. About $90 \%$ of all injuries occur in low- and middle-income countries and have been steadily increasing over the recent years (World Health Organization [WHO], 2014).

The severity of injuries can be reduced through adequate prehospital emergency care. In the case of accidents, many people die of injuries that are survivable (Wilson et al., 2015). Globally, road traffic injuries are one of the leading causes of death for people between 5-59 years (Browne et al., 2014). Most deaths occur within the first hour of the accident due to airway compromise, respiratory failure or uncontrolled hemorrhage. These injuries may be quickly addressed with basic first aid knowledge. Early and rapid care measures are likely to improve the possibility of survival, as compared to more advanced efforts at a later stage (Wilson et al., 2015). Patients with life-threatening injuries have a mortality rate of 6\% in countries with well-educated prehospital ambulance staff, as compared to countries with little or no advanced prehospital ambulance staff with a mortality rate of 36\% (WHO, 2014).

The complexity of the care of patients affected by trauma requires that caregivers have relevant education (Steinemann et al., 2011). Higher education and continuing education of nurses in trauma care have been shown to improve the care and the outcome for trauma patients (WHO, 2014). By legislation from 2005, there must be a registered nurse in every Swedish ambulance (SOSFS, 2000:1). World health organization (WHO, 2008) states that all Member States of the European Union should introduce and regulate specialist training for all prehospital emergency care personnel. The quality of prehospital emergency care must be guaranteed, and all emergency medical care measures should be provided by staff that is trained in prehospital care (WHO, 2008). The Swedish National Board of Health and Welfare (2015) points out that all prehospital caregivers should have adequate trauma training to improve trauma care. There is no standard that indicates how often continuing education should be offered. Knowledge and skills that are frequently used may require little updating. 
However, skills that are used less frequently should be trained more often (Gonzalez \& Kardong-Edgren, 2017).

Simulation is a suitable method for training of the prehospital staff since is not advisable to use real patients for training purposes, such as those who suffer from severe trauma requiring immediate care (Steinemann et al., 2011). Learning with simulation involves learning theory and practical skills that can be applied and integrated with already existing skills (Garvey, Liddil, Eley \& Winfield, 2016). The simulation creates experiences. It involves understanding how disease or injury can be experienced, integrated with the knowledge of the actual injury or disease (Benner \& Tanner, 1987). In the simulation, caregivers learn to integrate thought, feeling, and action, which can then be translated into patient-centered care measures.

Improving the ambulance staff's knowledge and skills of care of patients affected by trauma can be a cost-effective way to improve patient outcomes. The nurses' theoretical and practical knowledge, as well as experience, are improved and maintained through training in a simulated environment. It is therefore of interest to study how nurses experience trauma simulation.

The aim of this study was to examine how nurses in the ambulance service experienced participation in trauma simulation.

\section{Method}

This study had a quantitative design. Data were collected by participants performing simulated trauma care on four different occasions during a six-month period and directly after the last simulation rating three statements on a 5-point Likert scale. A descriptive and inferential analysis were conducted.

\section{Participants}

Participants in this study consisted of 61 nurses whereof 21 were registered nurses (34\%) with a three-year university education with a bachelor's degree. The additional 40 participants were specialist nurses (66\%) which is a registered nurse with specialist training and work experience from hospital-based emergency care and in addition, has a one-year universitylevel education with a focus on prehospital emergency care. This education includes a master's degree in prehospital emergency care. There were 36 males (59\%), and 25 females (41\%) and the ages ranged from 25-63 years (mean 39). The experience from prehospital 
emergency care ranged from 0-36 years (mean 9). All participants received oral information about the study and were then asked to participate voluntarily. Inclusion criteria were registered nurses working in an emergency ambulance service, participating in a low fidelity trauma simulation in a prehospital setting. All participants had previous experience of simulation training which could strengthen validity (Polit \& Beck, 2017).

\section{Data Collection}

The participants performed simulated trauma care on four different occasions during a sixmonth period. The simulated patient scenarios consisted of a range of typical prehospital injuries, for example; closed pelvic fracture, penetrating abdominal wounds and open extremity fractures. All patient scenarios were represented by a Resusci Anne Basic manikin (Laerdal ${ }^{\circledR}$ Stavanger) with moulage injuries.

Before the first simulation and again directly after the last simulation, participants were asked to rate three statements on a 5-point Likert scale, ranging from "strongly disagree” to "strongly agree”. By using the same questions in the before and after rating strengthened the reliability (Polit \& Beck, 2017). The statements were asked in the form of assertions and aimed at answering the participants' perceptions of trauma simulation. The statements were:

- I think simulation of severe trauma with manikins is realistic

- Simulation is a suitable method for learning severe trauma care

- I am comfortable in the situation learning severe trauma care through simulation

\section{Data Analysis}

The descriptive and inferential analysis was conducted using IBM Statistical Package for the Social Sciences (SPSS) 24.0. Descriptive analysis (central tendency and distribution) were used to describe the data, whereas inferential statistics (Paired sample t-Test) compared potential differences between the groups. The level of significance used was set at $\alpha=0.05$.

\section{Ethical consideration}

The study followed the ethical principals in accordance with the World Medical Association (2013) about anonymity and integrity. Ethical approval was obtained from an Internal Review Board. Participants were given full information about the study before the simulation started. Informed consent was obtained from each participant. 


\section{Results}

The results show that there are statistically significant differences between the pre- and posttest regarding all three statements. The realism of simulated trauma care on a manikin increased from pre- to post-test with mean .23 (6\%) on a 5-point Likert scale. Simulation as a suitable method for training and learning trauma care was on a 5-point Likert scale rated mean 4.69 in the post-test which was an increase of 1.3 (38\%) from the pre-test. The participants' experiences of being comfortable in the simulated trauma situation were rated mean 4.64 in the post-test which was an increase of .74 (19\%) on a 5-point Likert scale compared to the pre-test (table 1).

Table 1. The participants' rating statements on a 5-point Likert scale (strongly disagree to strongly agree) presented as mean for pre- and post-test.

\begin{tabular}{|l|l|l|l|l|l|}
\hline Statements & $\begin{array}{l}\text { Pre-test } \\
\text { mean } \\
(\text { SD) }\end{array}$ & $\begin{array}{l}\text { Post-test } \\
\text { mean } \\
(\text { SD) }\end{array}$ & Sig & $\begin{array}{l}\text { Mean } \\
\text { Increase }\end{array}$ & $\begin{array}{l}\% \\
\text { Increase }\end{array}$ \\
\hline $\begin{array}{l}\text { I think simulation of severe trauma with } \\
\text { manikins is realistic }\end{array}$ & $\begin{array}{l}3.85 \\
(1.01)\end{array}$ & $\begin{array}{l}4.08 \\
(.78)\end{array}$ & $.00^{*}$ & 0.23 & $6 \%$ \\
\hline $\begin{array}{l}\text { Simulation is a suitable method for } \\
\text { learning severe trauma care }\end{array}$ & $\begin{array}{l}3.39 \\
(.88)\end{array}$ & $\begin{array}{l}4.69 \\
(.62)\end{array}$ & $.00^{*}$ & 1.3 & $38 \%$ \\
\hline $\begin{array}{l}\text { I am comfortable in the situation } \\
\text { learning severe trauma care through } \\
\text { simulation }\end{array}$ & $\begin{array}{l}3.90 \\
(.91)\end{array}$ & $\begin{array}{l}4.64 \\
(.63)\end{array}$ & $.00^{*}$ & 0.74 & $19 \%$ \\
\hline
\end{tabular}

*Paired t-test

\section{Discussion}

By creating a simulated environment where clinical practice can be realistically trained, participants can better understand and handle different situations when they later arise in real clinical practice. Realism gives participants an enhanced interaction with patients, as well as relatives and colleagues during simulation. It means being prepared for future events (Jeffries, 2016). In the results of this study, participants expressed that simulation of severe trauma with manikins was realistic. The experience of realism means that the simulation is meaningful (Allan et al., 2010). Participants become more motivated to learn and therefore benefit from improved learning (Abelsson, Rystedt, Suserud \& Lindwall, 2016).

In this study, it emerged that the rating of simulation as a suitable method for training and learning trauma care increased by $38 \%$. This is consistent with previous research that 
demonstrated how simulation improves both theoretical knowledge and practical skills but also increases participants' confidence in critical care environments (Brien, Charette \& Goudreau, 2017). A simulation is a good option for teaching inexperienced staff to handle complex healthcare situations (Boling \& Hardin Pierce, 2016). Learning through simulation does not require the staff to be exposed to emergency care at accident sites, with real patients. The simulated learning environment is safe not only for the patient but also for teaching the prehospital staff (Abelsson et al., 2016).

Being comfortable or not in the simulation can depend on the participants' level of anxiety, which is a feeling of insecurity due to the inability to predict or control the temporary situation that one faces (Allen et al., 2010). Being uncomfortable during simulation has been described as an emotional reaction to being embarrassed. When the participants feel embarrassed, the result will be that they focus on their own feelings instead of on the learning (Abelsson \& Bisholt, 2017). Learning is then obstructed due to the negatively affected cognitive functions (Vytal, Cornwell, Arkin \& Grillon, 2012). Fear of failure or negative assessment (Keitel et al., 2011) during simulation can also result in participants being physically affected by increased heart rate (Bauer et al., 2016).

Previous research has described how participants experience comfort when simulated patient scenarios are presented at a level of knowledge appropriate for each one of the participants (Abelsson \& Bisholt, 2017). Patient scenarios based on prior knowledge may stimulate an enhancement in clinical decision making and interventions. However, patient scenarios should challenge and be more difficult than the participants can manage, to induce learning (Adams Miller, Kimble, Sudia \& Gee, 2016). When participants are outside their comfort zone, challenging patient scenarios can lead participants to manage new care situations (McLellanda et al., 2017; Miyasaka, Martin, Pascual, Buchholz \& Aggarwal, 2015). It allows participants to explore their knowledge boundaries and provides the opportunity to understand the need for additional knowledge (McDermott, 2016).

\section{Limitations}

A limitation is that the nurses in the study had varying experiences of trauma patients in clinical practice, as well as from simulating trauma care. This may have affected the result.

\section{Conclusions}

With the experience of realism in simulation, participants become more motivated to learn and prepare for future events. A simulation is an option for teaching staff to handle complex 
healthcare situations. Being uncomfortable or experiencing anxiety during simulation is an emotional reaction expressed as the feeling of embarrassment. When the participants feel uncomfortable, the result is that they focus on their own feelings instead of the learning. Participants learn better from simulation when they are outside their comfort zone but without being uncomfortable or experiencing anxiety.

Conflict of interest - The authors declare that there is no conflict of interest.

Source of funding - This research received no specific grant from any funding agency in public, commercial or not-for-profit sectors.

\section{References}

Abelsson, A., \& Bisholt, B. (2017). Nurse student's learning acute care by simulation. Focus on observation and debriefing. Nurse Education in Practice, 24, 6-13.

Abelsson, A., Rystedt, I., Suserud, BO., \& Lindwall, L. (2016). Learning by simulation in prehospital emergency care - an integrative literature review. Scandinavian Journal of Caring Sciences, 30(2), 234-240.

Adams Miller, B., Kimble., L. P., Sudia, T., \& Gee, R. M. (2016). A Phenomenological Inquiry of the Perceptions of Simulation among ADN Students with Prior Health Care Experience. Teaching and Learning in Nursing, 11(4), 189-193.

Allan, C. K., Thiagarajan, R. R., Beke, D., Imprescia, A., Kappus, L. J., Garden, A., Hayes, G., Laussen, P. C., Bacha, E., \& Weinstock, P. H. (2010). Simulation-based training delivered directly to the pediatric cardiac intensive care unit engenders preparedness, comfort, and decreased anxiety among multidisciplinary resuscitation teams. The Journal of thoracic and cardiovascular surgery, 140(3), 646-652.

Bauer, C., Rimmele', T., Duclos, A., Prieto, N., Cejka, J. C., Carry, P. Y., Grousson, S., Friggeri, A., Secco, J., Bui-Xuan, B., Lilot, M., \& Lehot, J. J. (2016). Anxiety and stress among anaesthesiology and critical care residents during high-fidelity simulation sessions. Anaesthesia, critical care \& pain medicine, 35(6), 383-392. 
Benner, P., \& Tanner, C, (1987). Clinical judgment: how expert nurses use intuition. The American Journal of Nursing, 87(1), 23-31.

Brien, L. A., Charette, M., \& Goudreau, J. (2017). Nursing students’ perceptions of the contribution of high-fidelity simulation and clinical placement in a critical care course. Clinical Simulation in Nursing, 13(9), 436-441.

Boling, B., \& Hardin-Pierce, M. (2016). The effect of high-fidelity simulation on knowledge and confidence in critical care training: An integrative review. Nurse Education in Practice, 16(1), 287-293.

Browne, L. R., Keeney, G. E., Spahr, C. D., Lerner, E. B., Atabaki, S. M., Drayna, P., \& Cooper, A. (2014). Trauma care for children in the field. Emergency Medical Services for Children, 15(1), 38-48.

Garvey, P., Liddil, J., Eley, S., \& Winfield, S. (2016). Trauma tactics: rethinking trauma education for professional nurses. Journal of Trauma Nursing, 23(4), 210-214.

Gonzalez, L., \& Kardong-Edgren, S. (2017). Deliberate practice for mastery learning in nursing. Clinical Simulation in Nursing, 13(1), 10-14.

Jeffries, P. R. (Ed.). (2016). The NLN Jeffries simulation theory. Philadelphia, PA: Wolters Kluwer Health.

Keitel, A., Ringleb, M., Schwartges, I., Weik, U., Picker, O., Stockhorst, U., \& Deinzer R. (2011). Endocrine and psychological stress responses in a simulated emergency situation. Psychoneuroendocrinology, 36(1), 98-108.

McDermott, D. S. (2016). The prebriefing concept: A Delphi study of CHSE experts. Clinical Simulation in Nursing, 12(6), 219-227.

McLelland, G., Perera, C., Morphet, J., McKenna, L., Hall, H., Williams, B., Cant, R., \& Stow J. (2017). Interprofessional simulation of birth in a non-maternity setting for preprofessional Students. Nurse Education Today, 58, 25-31.

Miyasaka, K. W., Martin, N. D., Pascual, J. L., Buchholz, J., Aggarwal, R. (2015). A Simulation Curriculum for Management of Trauma and Surgical Critical Care Patients. Journal of surgical education, 72(5), 803-810. 
National Board of Health and Welfare. (2015). Trauma care during a serious event (in Swedish). Stockholm: National Board of Health and Welfare.

PHTLS $^{\circledR}$. (2014). Basic and advances prehospital trauma life support. Prehospital trauma life support committee of the national association of emergency medical technicians in cooperation with the committee on trauma of the American college of surgeons. (8th ed). St. Louis: Jones \& Bartlett Learning.

Polit, D. G., \& Beck, C. T. (2017). Nursing research: generating and assessing evidence for nursing practice. Philadelphia: Lippincott.

SOSFS. (2000:1) National Board of Health and Welfare regulations and guidelines on drug handling in health care (in Swedish). Stockholm: National Board of Health and Welfare.

Steinemann, S., Berg, B., Skinner, A., DiTulio, A., Anzelon, K., Terada, K., Oliver, C., Ho, H. C., \& Speck, C. (2011). In situ, multidisciplinary, simulation-based teamwork training improves early trauma care. Journal of Surgical Education, 68(6), 472-477.

Vytal, K., Cornwell, B., Arkin, N., \& Grillon, C. (2012). Describing the interplay between anxiety and cognition: from impaired performance under low cognitive load to reduced anxiety under high load. Psychophysiology, 49(6), 842-852.

WHO. (2014). Injuries and violence: the facts 2014. Geneva. World Health Organization. WHO. (2008). Emergency medical services system in the European Union. Report of an assessment project co-ordinated by the World Health Organization. Denmark: World Health Organization.

Wilson, M. H., Habig, K., Wright, C., Hughes, A., Davies, G., \& Imray, C. H. E. (2015). Prehospital emergency medicine. Lancet, 386(1002), 2526- 2534.

World Medical Association. (2013). Declaration of Helsinki. Ethical Principles for Medical Research Involving Human Subjects. Journal of the American Medical Association, 310(20), 2191-2194. 